Zhang Biyun. (2020). Chinese Culture in Traditional Clothing-By Taking Cheongsam for Example. Eurasia: current issues of cultural heritage. Collection of Scientific Articles. European Scientific e-Journal, 3 (3), 32-42. Hlučín-Bobrovníky: "Anisiia Tomanek" OSVČ.

DOI: $10.47451 / \operatorname{art} 2020-10-001$

EOI: $10.11244 / \operatorname{art} 2020-10-001$

The paper is published in Crossref, Internet Archive, Google Scholar, Academic Resource Index ResearchBib, JGate, ISI, CiteFactor, ICI, eLibrary databases.

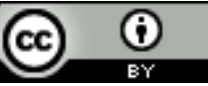

Zhang Biyun

Associate Professor, Candidate of Art History Member of the Association of Art Critics (AIS)

Member of the International Union of Teachers and Artists

College of Art, Zhejiang University of Technology

Hangzhou, Zhejiang, China

E-mail: zhangbiyun2013@163.com

\title{
Chinese Culture in Traditional Clothing-By Taking Cheongsam for Example
}

\section{Abstract:}

Every country has its own unique culture. For China, a country with a long history and a separate cultural system, the traditional clothing can best reflect its cultural characteristics of different periods. For example, cheongsam, as a product of the most turbulent period in Chinese history, has established its unshakable status with its unique beauty, and has become a symbol of unique oriental charm. In this paper, we will interpret the unique Chinese cultural deposits contained in the development history of cheongsam. The author concludes that the classic cheongsam style can show the female beauty moderately, without showing the chest, waist, hip and legs exaggeratedly, and give expression to the introverted, self-confident and simple temperament of Orientals in a simple and natural style. Compared with the protruding chest and back of western dresses, the magical charm of cheongsam lies in the display of the waist and hip curves, so people with a longer waist look more attractive when wearing cheongsam, which just conceals the shortcomings of the lower hip line of eastern women.

\section{Keywords:}

cheongsam, style, traditional culture.

\section{Introduction}

Chinese culture and art are a unique heritage of the world community. Chinese way of life has centuries-old origins and retains its individuality and uniqueness despite numerous attempts by Western civilizations to exert a tangible influence in order to transform Chinese culture to the standards and patterns of their values. In 
the era of digitalization and total informatization of the world community, it is extremely important not only to preserve national historical values that are expressed in household items and clothing, but also to study the features of historical styles, which can be used to create new ones, thereby preserving the cultural foundations and promoting them in modern society. One of the main and important components of culture is clothing. The study of historical clothing styles helps to preserve national identity and explore important aspects of the culture and art of a particular era of civilization. For example, cheongsam, as a product of the most turbulent period in Chinese history, has established its unshakable status with its unique beauty, and has become a symbol of unique oriental charm. In this paper, we will interpret the unique Chinese cultural deposits contained in the development history of cheongsam.

\section{Development History of Cheongsam}

As an important part of showing national culture, clothing not only displays culture in the most intuitive way, but also contains numerous material and intangible cultural heritages. As the last dynasty in China's feudal history, the Qing Dynasty played a unique role in China's cultural system, while the clothing worn by the Manchus gradually blended with the Han culture and became a typical China's traditional clothing. The popularity of cheongsam began in the late Qing Dynasty. Under the impact of foreign culture, cheongsam was improved according to their aesthetics.

\section{(1) Classical Period}

In the history of ancient Chinese clothing, the most important forms of clothing are 'Bianfu' (a clothing for nobles in the ancient time), 'Shenyi' (ancient Chinese robe) and 'robe'. The robe has a quite long history and can be traced back to about 3000 years ago. According to the record in The Book of Odes. Odes of Qin. Wuyi, "I would like to share the robe and the undershirt with you". The robe is a long dress that can be cut from the shoulder to the ankle regardless of the upper and lower garments, and was originally unisex. Robes were originally used as private clothing or linings for nobles, but not as formal clothing. They were used as formal clothing in the Eastern Han Dynasty and began to evolve from underwear to outerwear. For thousands of years, the formal dresses of women in the early time were made in the form of robe.

After the Manchus entered the Central Plains, their national clothing became one of the main clothing. Nurhachi completed the unification of Jurchen in 1583 and established the 'Niru' Eight Banners system. Therefore, the Manchus are also 
called the banner people, and the clothing they wear is also collectively called the Manchu clothes.

At first, the outer contour of Manchu clothing was rectangular, with a wide lower hem and slits around the hem, and it was a straight robe. The cuffs have semicircular sleeve caps about half a chi long, which resemble horseshoes and are commonly known as 'horse-hoof sleeves'. The overall fabric is mainly fur, with little decoration. These clothing characteristics are largely related to the Manchus' living habits. Before entering the Central Plains, the Manchus lived in the Northeast Region with a cold climate, especially in winter. Therefore, they must have adequate coldresistant clothing. The Manchus are good at riding and archery. For a riding and archery nation, all clothing shall be suitable and neat, which is conducive to galloping on a horse. Therefore, the overall Manchu traditional robes were designed according to their lifestyles. With the establishment of the Qing Dynasty, the whole Manchu people began to move to the south, and the change of climate also affected the change in lifestyles. Riding and archery gradually faded out from the original lifestyle. With the infiltration of Han culture, the traditional clothing of the Manchus was gradually influenced by the Han people. While retaining their own national customs and etiquette, they also absorbed a large number of Han cultures. From the establishment of the Qing Dynasty to the end of the Qing Dynasty, a series of changes took place in the shape and decoration of robes of the banner people, and the influence of Han culture was reflected on the fabric, the shape and the decoration.

The unique robe of the Qing Dynasty changed from the initial appearance characteristics determined by the specific climate and lifestyle to the symbol of the noble status of the royal family, demonstrating the profound influence of the Han culture. Its original simple and practical features were gradually replaced by overelaborate and luxuriant decoration. For example, the horse-hoof sleeves, used to adapt to winter outing, riding and hunting in the north, were originally designed to protect the back of the hands from freezing, and to facilitate the warmth of the hands in the sleeves. In the later period, the horse-hoof sleeves were only reserved for official uniforms or people with status in the Qing Dynasty. When they met superiors or elders, they would not wear them. The function of this clothing feature gradually fades and becomes a symbol of status. This shows that the function of clothing will change according to the needs of the society.

Cheongsam, as a traditional Manchu clothing, was originally unisex. The robes worn by women were later decorated differently from those worn by men, with slits on all sides changed into straight-through styles. After continuous improvement, it 
was finally different from men's robes and became a unique female style, gradually becoming a typical dress of Manchu women, which gradually becomes a cheongsam known by the public nowadays, and a typical oriental dress.

(2) Transition Period

The name of cheongsam appeared around the 1920s. In the Qing Dynasty, the clothes worn by women were called "chemise" and "cloak dress" according to their functions. In the early Republic of China, the name of cheongsam was created to locate this kind of clothing exclusively for the Manchus.

According to the records, from the 1920s to the 1950s, the style of cheongsam was not really fixed, but changed with changes in policies. The initially popular cheongsam still followed the conservative style. The robe was wider and close to the vamp in length, with trousers worn inside. However, the cheongsam soon began to change in structure and changed all the time, including the height of the collar, the narrowing and shortening of the sleeves, the scaling of the waist, the length of the robe, the height of the slits, and the amount of the hem.

When short skirts emerged in the western women's clothing, cheongsam was also affected, and became shorter, with a length of only one or two cun above the knee, the trousers inside were discarded, and women began to wear silk stockings.

As the government of the Republic of China established its capital in Nanjing, and became more stable politically, the government issued rules on clothing and promulgated clothing regulations. It is stipulated that women's cheongsam should extend between the knee and the ankle, with long trousers worn underneath, and should be made of blue fabrics. The high-quality homespun advertised by national industrialists at that time was called 'indanthrene', which was the representative of this blue fabric. This indanthrene is a kind of blue-based cotton, silk, wool and other fibers and textiles dyed with organic synthetic dyes from India. At that time, under the vigorous promotion of the government, female students and a group of young ladies loved to cut their clothes with this fabric. Japanese scholar Kyousuke Ueda once mentioned in the Chinese Art Illustration that "China becomes a blue-clothed race of 400 million people. When crossing the Yalu River, it is a quite different feeling when suddenly moving from the white-clothed country (South Korea) to the blueclothed mainland". Apparently, during this period, almost all clothing, including cheongsam, was mainly blue. However, such policies cannot stop people from pursuing beauty. In the summer of 1929, a kind of 'Naimei Clothing' shocked Changsha. At that time, Shanghai film actress Yang Naimei went to Hunan Province for show. The clothing she worn was as thin as a cicada's wings, with visible skin, exposed chest and back, length above the knee and no skirt underneath. Women in 
Changsha started to learn this style. The Public Security Bureau deemed it immoral and immediately banned this kind of dressing, but we can see that the western emancipation thought had a far-reaching influence on China at that time.

By observing the ever-changing changes of cheongsam at that time, we can feel that the changes in women's mind at that time were beyond the control of the government. After decades, the style of cheongsam was roughly established.

At that time, according to the different styles of cheongsam, cheongsam was roughly divided into Beijing style and Shanghai style. The Beijing style cheongsam was an improved version of the Qing Dynasty cheongsam at that time, with an obvious traditional style, which is obviously the maintenance and continuation of a tradition. However, the pursuit of independence and reverence for art by some women in Shanghai led to a significant change in the structure of the cheongsam. The cheongsam was transformed from the original 'cross plane structure' to the western structure with split body, split sleeve and seams, completing a combination of Chinese and Western elements.

The 1920s saw a turbulent period in Chinese history. The Beiyang Government and the Nationalist government governed in the north and the south. There were constant struggles among warlords, and the feminist movement gradually rose. The fashion of women's clothing and even the trend of national institutions were full of uncertainty. The women's movement also reached its peak after the Nanjing government inherited the reign. The appearance of cheongsam with a revolutionary meaning swept the land of China and truly gained popularity among the people.

(3) Finalizing Period

It was a watershed for the improvement of the westernization of cheongsam from 1950s to 1970s. After the previous transition stage, the improvement of simple plane curve structure can no longer meet the needs of the three-dimensional process of cheongsam. It was possible to gain a chance of further development only by introducing the western-style structure completely. The cheongsam was pushed to the crossroad by the wheel of history, and finally the Hong Kong and Taiwan garment industry and academia jointly promoted the finalization of the structure.

There is no clear historical conclusion about the time node of the westernized improvement of cheongsam, but it is undeniable that during this period, the shoulder seam was broken in cheongsam, which significantly reduced the armpit drape; the chest and waist seams were introduced, resulting in a distinct chest and waist difference that highlights the chest shape; the appearance of the sleeve cap structure increased the fit between the shoulder and the arm. This change was not officially confirmed until 1974 under the discussion of the Taipei Chinese Cheongsam 
Research Association. The fixed pattern of cheongsam we can see nowadays was also determined at that time.

\section{Beauty of Cheongsam}

The beauty of cheongsam is spiritual. The Chinese cheongsam fully shows the beauty of oriental women. Cheongsam has a magical charm for the physical beauty of women. Wearing a cheongsam, the head, neck, shoulders, arms, chest, waist, hip, legs, hands, feet and other curves of women can be perfectly reflected. Everywhere there are distinctive cheongsam elements.

\section{(1) Beauty of the Front}

The front of the cheongsam varies in style. The front opening of Cheongsam usually includes round opening, crank opening, inclined opening, square opening, double opening, straight opening, Biwa opening, etc. The most common is the round-opening cheongsam, due to rounded and smooth lines and relatively simple craftsmanship. The crank opening is S-shaped, opening to the bottom and easy to wear. The inclined opening has very beautiful lines, and the double opening is relatively complicated in craftsmanship, looking noble and beautiful overall. For the Biwa-opening cheongsam, the front with buttons on the right only covers to the chest, and the arc does not fall under the armpit. The design of right-sided opening is generally adopted. The front type split structure just shows the effect of side opening in the style and shape. The side opening, as the dividing line on style, is disconnected, without considering the functionality of putting on and taking off. The change of the dividing line breaks through the traditional craft. The hems and patterns are matched according to the shape, and the decoration technique can also be recreated with modern aesthetics. In the modern design, the front is designed with multiple shapes, long and short, straight and inclined, square and round. Therefore, the shape of the front has become an important part to show the beauty of cheongsam.

The front of the cheongsam should be slack and tight. The placket was originally a very straight line, but gradually became smooth and arc-shaped, located on the right side of the cheongsam. The change in the front of the cheongsam complements other elements, and the front with the spirit of cheongsam has become an important element in the design.

(2) Beauty of the Collar

The collar is the soul of the cheongsam. There are many types of collars, and different clothing styles are suitable for different cheongsam shapes. For the choice of cheongsam, the collar is a very important reference factor. For example, the shape 
of a woman's face and the length of her neck are significant for the choice of a collar. The collar part of a cheongsam is to show the sexy beauty of a woman's neck, which contrasts with her lip and jaw, and is an important part to display the exquisite workmanship of a cheongsam. The beautiful and capable beauty is contained in the neatness and exquisiteness of the cheongsam. The change of the collar is very subtle. Most collars are mainly standing, and wrap around the neck, making the head noble and dignified. The shape of the collar is also ever-changing. In addition to high and low collars, the roundness of the collar corner, the change of the angle and the variety of styles are the highlights in the design of cheongsam. The high collar of the cheongsam can keep the dignity and beauty of the female figure, and the high-heeled shoes (if matched) can play a better effect of chest out and abdomen in. This is why cheongsam is generally worn with high-heeled shoes.

(3) Beauty of the Slit

If the collar part shows the dignified beauty of a cheongsam, the slits in the skirt's hemline show a hazy beauty. Cheongsam slits began in the 1920s, and have been changing with changes in aesthetic needs since then. Usually, the cheongsam has two slits, to facilitate movement and show slender legs. The beauty of cheongsam lies in its right exposure and cover while showing the curvaceous beauty of women. This design contains the subtle and gentle charm of oriental women. The slits of the cheongsam are mainly to meet the needs of functionality and aesthetics. It presents a sense of beauty and facilitates walking. The shape of the cheongsam hemline mainly includes wide and straight hemlines. The slits are divided into high slits and low slits. The high slit cheongsam shows the feminine and slender legs and curvaceous figure of women while facilitating walking. The beauty of the human body displayed by the cheongsam is precisely because it follows the elegance principle of beauty, virtue and moderation. This methodology of the elegance principle is just the attitude of moderation, which points out the way to elegance- elegance in exposure in the contradictory state of culture and appearance of the clothing culture.

\section{(4) Beauty of the Pattern}

In the Qing Dynasty, the Manchu women's clothing was bright and complex, with high contrast, and brightly colored hems were added to the neckline, sleeve caps and fronts. This color aesthetics of the Manchu nobility, through the combination of colors, presents the visual effect of enthusiasm or elegance. Embroidery, as an important means to show this beauty, embodies an art that exists in a certain cultural thinking and integrates traditional, cultural and folk techniques. For thousands of years, it has been living and developing in a specific environment. In recent years, influenced by Western culture, people have become obsessed with western-style 
dressing and abandoned the traditional hand embroidery that is considered 'rustic'. When looking back, we discover that we have abandoned a great treasure. The humane handmade products have comforted our withered hearts. The rise of traditional embroidery just shows our love for traditional culture and our desire to return to the humanistic spirit.

Thus, the traditional cheongsam is famous for its embroidery lace. The embroidery pattern, as a major feature of the cheongsam, is the most intuitive and easily recognizable element in the spirit of the cheongsam, which can best reflect the design style. In addition to decoration, it also has a wealth of implied meaning. For example, pines and cranes symbolize longevity; plum blossom, orchid, bamboo and chrysanthemum symbolize elegance and friendship; mandarin ducks and twin lotus flowers symbolize connubial love and harmony; pomegranates and grapes symbolize many children and grandchildren; phoenix and peony symbolize wealth and auspiciousness; butterflies symbolize spring scenery and fine view; magpies symbolize approaching good things. Later, embroidery gradually declined, and cheongsam was dominated by plain cheongsam and original colors. Later, it became popular again under the influence of fashion. Traditional embroidery is mostly used for decoration on the cuffs, chests or backs, showing an elegant and delicate charm through beautiful embroidery patterns.

\section{Oriental Spirit in Modern Cheongsam}

For thousands of years, under the constraints of decorative function and social structure, traditional Chinese costumes have evolved while inheriting traditions and absorbing foreign cultures, forming a traditional Chinese costume culture with grand content, unique style, superb skills and diverse styles. Cheongsam used to be a shining star in the long history of China's clothing culture, and its graceful and elegant styles once fascinated generations of people. During the Republic of China, the national government at that time designated cheongsam as women's dress, which was called the national dress for a while. Cheongsam is free in terms of style, color and decoration, and can best reflect the personality of the person wearing the clothing. It is the 'best clothing' that can best show the beauty of women, and has the most traditional Chinese characteristics and national representativeness. While absorbing foreign cultures, it has been improved and become a very excellent national costume and a typical symbol of oriental female beauty.

Cheongsam is a mirror of Chinese clothing culture, which records the time imprint of cultural development, and reflects the social production and aesthetic standards of different times. For more than 300 years, cheongsam has accompanied 
Chinese women through different historical periods. It has changed in the long river of history. Although cheongsam itself cannot speak, we can still understand the beliefs and aesthetic tastes of people in different times, different cultural backgrounds and different periods through this non-verbal information.

\section{(1) Practical Significance of Cheongsam}

In the current international environment, it is inevitable for any nation in the world to become unified with developed countries in the material field, and the globalization of economy and trade contributes to the homogeneity of lifestyles. The way of thinking, aesthetic taste, culture and art, and language expression seem to be moving in the same direction. While enjoying the convenience brought about by homogeneity, we have doubts about this unification and attachment to the rich national culture. Cultural diversity and cultural individuality have also been proposed. Similarly, in terms of clothing, it is difficult to imagine that the only Chinese civilization and Chinese clothing culture with uninterrupted civilization process in the world civilization will be unified and put an end by Western civilization and Western clothing culture. In this regard, exploring the past, present and future of national costumes becomes very meaningful. However, for a long time in the past, nationalization was just a slogan, and some people's cultural labels were even political chips. We feel passionate but stand still about the attempt at the past. Most of our attempts are childish and superficial, and just stay on the accumulation of cultural symbols rather than grasp the essence of traditional costume culture. Cheongsam is just the answer to such an attempt, because of its unique aesthetic and social value, which is of great significance to the cultural inheritance of traditional clothing.

(2) Social Value of Cheongsam

The social value of cheongsam can be divided into spiritual and material values. In terms of spiritual value, first of all, the respect for people is shown. Because Confucianism has consistently run through the entire process of Chinese traditional culture, its influence on clothing culture is also very far-reaching. Chinese traditional costume culture has also been deeply marked by Confucianism. In essence, Chinese culture is a ritual culture, and ancient Chinese costume culture can also be understood as a ritual culture. Therefore, clothing is not simply clothing but endowed with rich humanistic connotations, and linked with political ethics and even cosmology, so that the clothing function is subordinate to the social function. However, after thousands of years, it evolved into a rigid and decadent system of rigid hierarchy and elimination of human nature at the end of the Qing Dynasty. After entering the industrial society, it severely restricted the further development of economy, culture, sports and the military, becoming a sign of backwardness. Cheongsam shows the clothing's return 
and care for people, and completely breaks the feudal shackles bound upon Chinese women for thousands of years. It is a respect and praise for human beings, and a transformation to the exhibition of fashion and figure, which is of great epochmaking significance.

Next, cheongsam is an organic product of traditional culture and modern civilization. Because of the chaotic social conditions in the early Republic of China, the influence of freedom, equality, democracy ideas and feudal conservative forces, the worship and yearning of Western lifestyles, material culture, and the low level of productivity in the society, the oppression of the imperialist and the weakness of the ruling class, the society developed in an abnormal way in economy, culture and other fields. The same is true for clothing. The old clothing disintegrated, the new dress code had not yet been formed, and the clothing culture suffered an unprecedented impact. The new style cheongsam was conceived under this background. It absorbed many characteristics of the Qing Dynasty clothing, the so-called 'civilized new dress' and other fashionable clothing at that time, and finally developed maturely in combination with Western tailoring. The previous low-level aesthetic taste was changed, and the disordered state was integrated to form a healthy and upward aesthetic taste. Once this form appeared, it became popular throughout the country, and was widely imitated.

Therefore, cheongsam is a combination of Chinese, Manchu and foreign elements. It is a product of cultural fusion, the result of contradiction and reconciliation of various parties, the representative of multiculturalism as well as the result of the choice and creation of the times. As an outstanding representative and successful model of Chinese traditional culture creativity, it will also provide enlightenment for other excellent traditional costumes to inherit and develop in the new historical period.

\section{Conclusion}

Thus, in terms of material value, the classic cheongsam style can show the female beauty moderately, without showing the chest, waist, hip and legs exaggeratedly, and give expression to the introverted, self-confident and simple temperament of Orientals in a simple and natural style. Compared with the protruding chest and back of western dresses, the magical charm of cheongsam lies in the display of the waist and hip curves, so people with a longer waist look more attractive when wearing cheongsam, which just conceals the shortcomings of the lower hip line of eastern women. Due to the one-piece form of the dress, its modeling curve extends from the collar to the shoulders, the chest, waist and hips and then to the hem, with the 
beauty of calligraphic smooth lines, directly reflecting the characteristics of Chinese culture. Covering and exposing, reality and virtuality are just right, praising the beauty while retaining the dignified and elegant demeanor. Exquisite craftsmanship and the organic combination of materials and styles reflect the beauty of life. In the new century, it is worth pondering how to inherit and develop cheongsam, a traditional dress with unique charm.

\section{References:}

Bao Mingxin (2000). Shanghai Style Cheongsam in the First Half of the 20th Century. Art \& Design, 5, 12-21.

Chen Guoqiang (2016). Application of Manchu Costume Elements in Modern Women's Clothing Design. Progress in Textile Science \& Technology, 3, 35-37.

Lin Xinghong, Liu Wen (2017). A Brief Discussion on the Difference between Beijing Style Cheongsam and Shanghai Style Cheongsam. Shandong Textile Economy, 10, 57-60.

Liu Yu (2011). History of Chinese Cheongsam Culture. Shanghai: Shanghai People's Fine Arts Publishing House.

Qi Qi (2014). Innovation and Development of Chinese Traditional Cheongsam in Modern Dress Art. Master's Thesis of Nanjing Normal University, 3.

Shen Congwen (2002). Research on Ancient Chinese Clothing. Shanghai Bookstore Publishing House.

Tang Xinxing (2005). An Interpretation of the Aesthetic Cultural Connotation of Cheongsam.

Wuhan: Master's Thesis of Wuhan University.

Wang Yunying (1985). Manchu Costumes in the Qing Dynasty. Liaoning Nationality Publishing House.

Wang Yi, Zhang Tao (2011). Influence of Manchu Costume Elements on Modern Design. Art and Literature for the Masses, 22, 52-53.

Wang Ziqing (1975). A Textual Research on Women's Robes in Past Dynasties. Taipei: Chinese Cheongsam Research Association.

Wen Lan (2009). Cultural Characteristics of the Inheritance and Development of Manchu Costumes in Modern Clothing Design. Manchu Minority Research, 2, 108110.

Yang Chenggui (1975). Theory and Practice of Cheongsam Tailoring. Taipei: Chinese Cheongsam Research Association.

Yuan Xuanping (2016). Cheongsam of the Republic of China and Shanghai Style Culture. Art \& Design, 4, 24-29. 
Zhu Bowei (2016). Research on the Structure of Cheongsam in Three Periods. Master's Thesis of Beijing Institute of Fashion Technology, 12.

Zhuang Lixin (2008). Changes in the Shape and Structure of Shanghai Style Cheongsam. Journal of Silk, 9, 51-52. 